\title{
An unusual presentation of degenerating fibroid
}

\author{
Neha V. Bhave*, P. K. Shah, Hemangi Chaudhari
}

Department of Obstetrics and Gynecology, Seth G. S. Medical College and King Edward Memorial Hospital, Parel, Mumbai, Maharashtra, India

Received: 26 December 2015

Accepted: 16 January 2016

*Correspondence:

Dr. Neha V. Bhave,

E-mail: nehabhave17@gmail.com

Copyright: () the author(s), publisher and licensee Medip Academy. This is an open-access article distributed under the terms of the Creative Commons Attribution Non-Commercial License, which permits unrestricted non-commercial use, distribution, and reproduction in any medium, provided the original work is properly cited.

\section{ABSTRACT}

Degeneration in a fibroid is seen when the blood supply falls inadequate to support the center of fibroid. Usually degeneration in a fibroid requires a symptomatic medical management. This is a case report of a degenerating fibroid that uncommonly presented in postpartum period as a retroperitoneal abscess requiring exploratory laparotomy.

Keywords: Fibroid, Degeneration, Retroperitoneal abscess, Exploratory laparotomy

\section{INTRODUCTION}

Leiomyoma or fibroid is the most common pelvic tumor of uterus and female pelvis. Being the most common tumor its etiology is not well understood. Degeneration occurs when there is lack of blood supply to the fibroid as it grows in size. It causes increase in morbidity rarely causing mortality. ${ }^{1}$ Degeneration is seen commonly during pregnancy and is known as red or carneous degeneration of fibroid or necrobiosis characterized by pelvic pain, fever and elevation of white blood cell count.

\section{CASE REPORT}

A 35years female in lactation amenorrhea came to emergency department with complains of pain in abdomen and backache for 1 month, aggravated since last 4 days and fever since last three days. She had delivered vaginally 3 months back with no complaints of puerperal fever, postpartum hemorrhage etc. On examination, she was vitally stable except for tachycardia. On abdominal examination, her abdomen was soft, non-tender. A vague mass was palpable which was arising from pelvis in right iliac fossa extending up to umbilicus. It was firm in consistency, immobile with vague margins. On vaginal examination, uterus was anteverted and a $10 \times 15 \times 10 \mathrm{~cm}$ mass was palpable in the right fornix which was fixed and minimally tender. It was firm in consistency and was not separately felt from uterus. Left fornix was free and non-tender.

On admission in ward, she had repeated spikes up to $38^{\circ} \mathrm{C}$. All Fever routine investigations like peripheral smear for malaria parasite, Leptospirosis antigen, Dengue, Optimal Antigen, Widal test sent on each spike were negative. All routine investigations were in normal range, except for white blood cell count which showed an increasing trend. There was no positive response to higher antibiotics and anti-malarial drugs. Ultrasound pelvis was suggestive of a right ovarian mass, measuring $8 \times 5 \mathrm{~cm}$ in size, most likely of inflammatory origin. Serum CA-125 was increased (144). On MRI scan (Figure 1), there was a large collection seen in right posterior pararenal space with fluid air within. A thin rim of enhancement and peripheral septations were seen. The lesion was anteriorly displacing the right kidney, ascending colon and ileocaecal junction. Inferiorly, it was extending into the pelvis up to the roof of the bladder. The lesion was adherent to the right side of the uterus but right adnexa also cannot be visualized. There was no 
abnormality of liver, pancreas, spleen and kidney seen. No ascites, no lymphadenopathy seen.
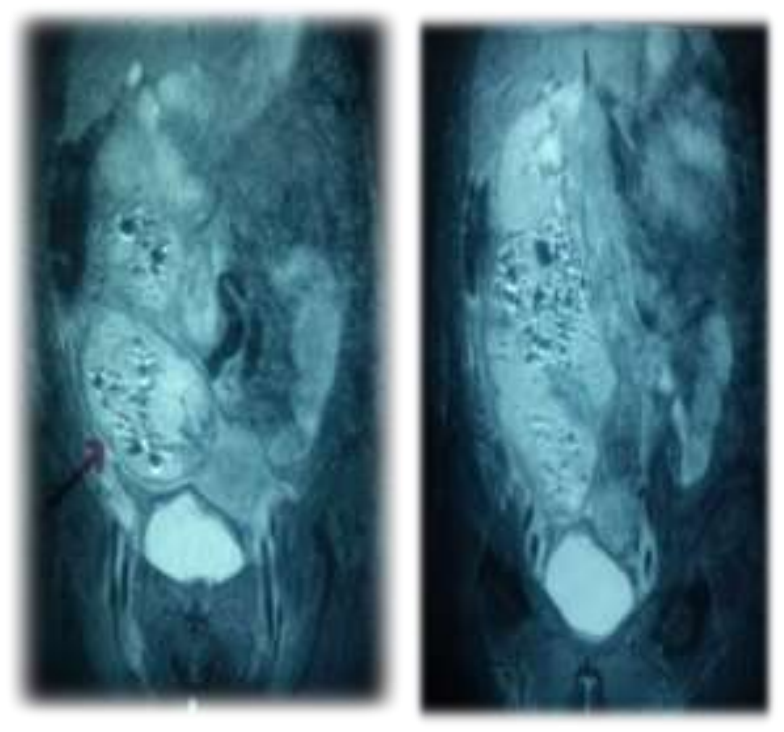

Figure 1: MRI plates showing; A: mass adherent to right side of uterus (marked by red arrow); B: showing collection in right posterior para-renal space.

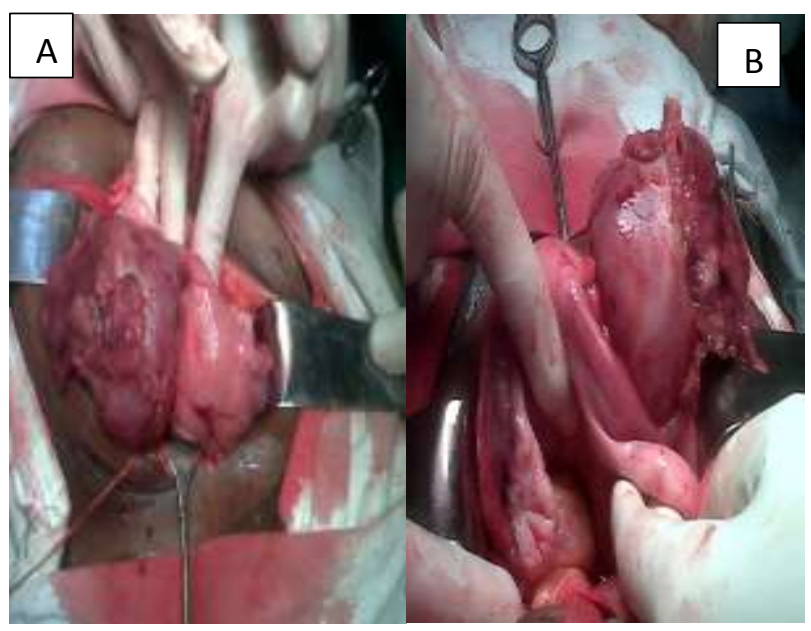

Figure 2: A \& B: Intraoperative pictures showing mass in the right broad ligament arising from uterus most likely to be a fibroid.

A decision for Exploratory Laparotomy was taken with multidisciplinary approach. Intraoperative a broad ligament mass of $10 \times 8 \times 8 \mathrm{~cm}$ was seen arising from the myometrium of right lateral uterine wall below the level of fallopian tube, most likely a fibroid (Figure 2). It appeared degenerated with pus extruding from it which was tracking up to retro peritoneum on right side and upwards up to the lower pole of right kidney. The mass was excised and sent for frozen section was suggestive benign spindle cell leiomyoma. Ileum, caecum and ascending colon were mobilized thereby exposing right retro peritoneum and right Para-nephric space. Pus was drained and two drains were kept, one in cavity created in broad ligament after fibroid excretion and other in right Morrison's space.

Patient had quick recovery post exploration. Postoperative course was uneventful. Histopathology report of the mass sent was suggestive of red degeneration of benign spindle cell leiomyoma.

\section{DISCUSSION}

Uterine fibroids, also known as leiomyomas or myomas are benign, monoclonal, smooth muscle tumors of the myometrium. ${ }^{2}$ These tumors may occur in isolation or as multiple growths of varying size, shape and location throughout the uterine musculature. They can be asymptomatic or can also present with symptoms of heavy bleeding, pelvic pressure, infertility etc. Degenerative changes in a fibroid occur when the size of the tumor outgrows its blood supply leading to necrosis of the tissue in it. The most common type of degenerative changes in fibroid is a hyaline degeneration. ${ }^{3}$ Only red degeneration and sarcomatous degeneration are usually symptomatic.

Pregnancy is characterized by increase in size of fibroid, commonly in first trimester. ${ }^{4-6}$ This may be related to effects of rising levels of human chorionic gonadotropin, receptors of which have been found in leiomyoma cells. ${ }^{7}$ Degenerative changes in fibroid during pregnancy are called as Red or Carneous degeneration. The exact mechanism is not completely understood, one hypothesis being venous obstruction at the periphery of lesion leading to hemorrhagic infarction and necrosis. It present with symptoms such as abdominal pain, tenderness, mild fever and increased white blood cell count. They are managed symptomatically with rest and analgesics. Fibroids with intractable pain not responding to medical management, rapid growth in size, a very large fibroid needs surgical management. ${ }^{8}$

Infections spreading to the fibroid are more common if it is in submucosal region. Most commonly seen in pedunculated submucosal fibroid which is protruding in vagina. The organism isolated from an infected fibroids are diverse can be gram positive, gram negative, aerobic and anaerobic bacteria (Clostridium species, Staphylococcus aureus, Streptococcus hemolyticus, Proteus species, Streptococcus agalactiae, Enterococcus faecalis, E. coli, Bacteroides fragilis. ${ }^{9-11}$ An infection can be associated with following clinical conditions like postpartum ascending uterine infection, abortion, postmenopausal, following uterine artery embolization and bacteremia in intravenous drug abusers. ${ }^{9,12-15}$ The possible routes of spread of infection to fibroid can be from endometrial cavity, direct extension from adjacent bowel or adnexa, hematogenous or lymphatic spread from infection elsewhere in the body. ${ }^{9,15}$ A separation of infected fibroid in puerperal period can present with late postpartum hemorrhage. ${ }^{16}$ 


\section{CONCLUSIONS}

This is an atypical case of red degeneration of fibroid which on superimposed infection presented as a retroperitoneal abscess, requiring surgical management. In this case could be hematologic or direct spread of infection to the fibroid during puerperal period.

Funding: No funding sources

Conflict of interest: None declared

Ethical approval: Not required

\section{REFERENCES}

1. Gupta S, Manyonda IT. Acute complications of fibroids. Best Pract Res Clin Obstet Gynaecol. 2009;23(5):609-17.

2. Hashimoto K, Azuma C, Kamiura S. Clonal determination of uterine leiomyomas by analyzing differential inactivation of the X-chromosome-linked phosphoglycerokinase gene. Gynecol Obstet Invest. 1995;40:204.

3. Ueda H, Togashi K, Konishi I. Unusual appearances of uterine leiomyoma: MR imaging findings and their histopathologic backgrounds. Radiographics. 1999;19 SpecNo:S131-45.

4. Lev-Toaff AS, Coleman BG, Arger PH. Leiomyomas in pregnancy: sonographic study. Radiology. 1987;164:375-7.

5. Rosati P, Exacoustos C, Mancuso S. Longitudinal evaluation of uterine myoma growth during pregnancy. J Ultrasound Med. 1992;11:511-5.

6. Aharoni A, Reiter A, Golan D. Patterns of growth of uterine leiomyomas during pregnancy: a prospective longitudinal study. $\mathrm{Br} \mathrm{J}$ Obstet Gynaecol. 1988;95:510-3.

7. Horiuchi A, Nikaido T, Yoshizawa T. HCG promotes proliferation of uterine leiomyomal cells more strongly than that of myometrial smooth muscle cells in vitro. Mol Hum Reprod. 2000;6:5238.

8. King R, Overton C. Management of fibroids should be tailored to the patient. Practioner. 2011;255(1738):19-23,2-3.

9. Genta Pedro R, Dias ML, Janiszewski TA, Carvalho JP, Arai MH, Meireles LP. Streptococcus agalactiae endocarditis and giant pyomyoma simulating ovarian cancer. South Med J. 2001;94:508-11.

10. Zangeneh M, Mahdavi AA, Amini E, Siadat SD, Karimian L. Pyomyoma in premenopausal woman with fever of unknown origin. Obstet Gynecol. 2010;116(2):526-8.

11. Fenney JG, Basu SB. Bacteroides infection in fibroids during puerperium. BMJ. 1979;2:1038.

12. Mason TC, Adair J, Lee YC. Postpartum pyomyoma. J Natl Med Assoc. 2005;97:826-8.

13. Sah SP, Rayamajhi AK, Bhadani PP. Pyomyoma in a postmenopausal woman: a case report. Southeast Asian J Trop Med Pub Health. 2005;36:979-81.

14. Kitamura Y, Ascher SM, Cooper C, Allison SJ, Jha RC, Flick PA. Imaging manifestations of complications associated with uterine artery embolization. Radiographics. 2005;25(Suppl. 1):S119-32.

15. Greenspoon JS, Ault M, James BA, Kaplan L. Pyomyoma associated with polymicrobial bacteremia and septic shock: case report and review of literature. Obstet Gynecol Surv. 1990;45:563-9.

16. Mukhopadhyay S, Arulkumaran S. Gynecological Disorders of pregnancy. In: S. Arulkumaran, Sivanesaratnam V, Chatterjee A, Kumar P, eds. Essential of Obstetrics. $1^{\text {st }}$ ed. New Delhi: Jaypee Brothers. 2004:199-200.

Cite this article as: Bhave NV, Shah PK, Chaudhari H. An unusual presentation of Degenerating Fibroid. Int J Reprod Contracept Obstet Gynecol 2016;5:5824. 